\title{
Mental Health in Hospitalised COVID I9 Patients in Quarantine During Second Wave in a South Indian Private Teaching Hospital
}

\author{
Sudakshina Chakrabarti (D) \\ Department of Anatomy, Saveetha \\ Medical College and Hospital, Chennai, \\ India
}

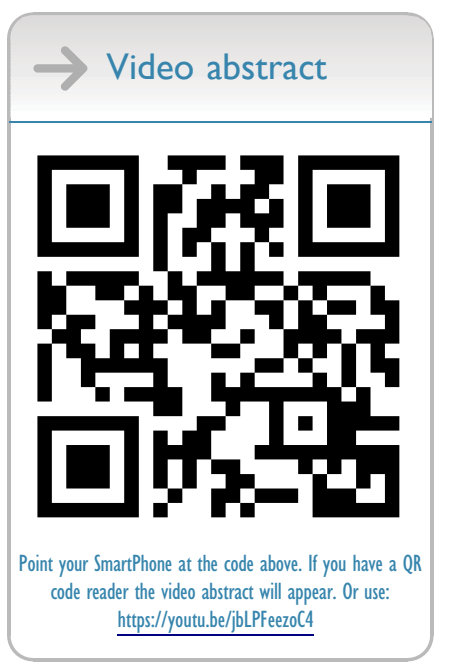

Correspondence: Sudakshina Chakrabarti Email sudhianat@gmail.com
Background: Covid 19 lockdown measures were taken all of a sudden during the devastating second wave in India, when there was a considerable loss and suffering in the country. The coronavirus disease 2019 (COVID 19) pandemic has led to unprecedented hazards to mental well-being globally.

Purpose: To assess the prevalence and evaluate risk factors of depression, insomnia or sleep disturbances and suicidal ideation among covid 19 positive patients admitted in covid wards with mild-to-moderate disease.

Materials and Methods: A total of 635 hospitalised patients who were covid-19 positive were requested to fill an online quality of life pre-validated questionnaire comprising of 4 sections the sociodemographic information section, health care assessment related to depression symptoms, insomnia assessment and assessment of suicidal ideation. The survey comprised of prevalidated questions on sociodemographics, knowledge of covid 19, fear of covid 19, insomnia, feeling of sadness, depression, feeling of rejection and suicidal ideation among the covid 19 positive inpatients in quarantine due to mild or moderate covid 19 disease.

Results: The prevalence of depression and insomnia or sleep disturbances after being diagnosed as covid 19 positive and hospitalized was nearly $40 \%$ and $28.8 \%$, respectively, among the inpatients. Depression was significantly observed in female group $(\mathrm{p}<0.001)$, unmarried or separated individuals $(\mathrm{p}<0.001)$, housewives $(\mathrm{p}<0.001)$ and patients with comorbidities $(\mathrm{p}<0.001)$. Insomnia was more likely to be present in elderly covid positive patients $(p<0.001)$ and separated or divorced group of participants $(\mathrm{p}<0.001)$. The prevalence of suicidal ideation was $5 \%$ of the total covid 19 positive patients participated in this study, and it was significantly observed among separated or divorced patients, cancer patients, patients from suburban residence and among graduates $(\mathrm{p}<0.001)$.

Conclusion: Covid 19 is associated with major psychological impact among the patients suffering from thus warrants counselling.

Keywords: questionnaire, Covid 19 positive patients, depression, insomnia, suicidal ideation

\section{Introduction}

In December 2019 there was a sudden rise in cases of pneumonia in Wuhan city, China which was later designated as Coronavirus disease by the World Health Organization (WHO) on 11 Feb 2020. This coronavirus is identified as a novel strain of coronavirus that shares $79 \%$ of genetic similarity with SARS- CoV from the SARS outbreak $2003 .{ }^{1}$

The mental well-being assessed in a Chinese study following Covid-19 as early as March 2020 showed that there was a considerable increase in negative feelings like depression, anxiety and fear of death both among the affected and unaffected 
population. Overall a decreased happiness and feeling of insecurity was reported to be high among the population. This anxiousness was more pronounced among the covid19 patients leading to self isolation, feeling of dejection, fear of infecting others even after they were cured and completed the quarantine period. $^{2}$

In a study from China, it was reported that $53.8 \%$ of Chinese people in general suffered from moderate to severe negative psychological effect related to COVID19. Further it was highlighted that $16.5 \%$ of the study participants had depression symptoms, $28.8 \%$ were in anxious states and $8.1 \%$ exhibited to have moderate to severe levels of stress. ${ }^{3}$

There are several causes which pose the current COVID-19 pandemic responsible for psychiatric consequences in the entire society. Human minds can get affected adversely due to the profound social impact of the pandemic and governmental response of repeated lockdown. The wellbeing of the infected and non-infected population is compromised as a result of widespread anxiety, fear of the virus, social isolation due to quarantine and travel restrictions by governments. Stress among the health-care workers and other essential workers also deserves special mention which has resulted due to limited health care resources, long stressful work hours, irregular pay and isolation from near and dear ones. The negative experiences specific to individuals who are infected with the covid-19 virus cannot be neglected. The complex emotions a covid-19 positive hospitalised patient faces are fear about the outcome of their illness, social stigma, fear of infecting others and fear of death are all of grave concern and can push them into depression and even selfharm and suicides. ${ }^{4,39}$

A review study by Vindegaard et al showed the prevalence of mental disorders among covid and non-covid affected population. The review revealed that there were profound mental problems among COVID-19 patients. $96.2 \%$ of covid-19 patients suffered from post-traumatic stress symptoms and 29.2\% from depression. Such negative emotions were found to be worse among covid-19 patients with prior psychiatric disorders. Among covid-19 positive patients with prior psychiatric disorders, $37.5 \%$ reported worsening of their eating disorder, 56.2\% had anxiety attacks and $20.9 \%$ showed worsening of their mental health. ${ }^{5}$

A meta-analysis was conducted as early as April 2020 which included analysing and synthesizing data from 13 studies comprising about 33,000 participants to investigate the prevalence of anxiety, depression and insomnia in health care workers who stand in the frontline during covid-19 crisis. In this analysis the pooled prevalence of anxiety symptoms in health care workers was found to be $23.2 \%$ in total 12 studies. The pooled prevalence of depression was $22.8 \%$ in ten studies and insomnia was observed to be prevalent in $38.9 \%$ of participants across 5 studies. ${ }^{6}$

India is a populated nation with marked diversity in the culture, belief, lifestyle, behaviour, and infrastructure related to healthcare. To begin with the country has a poor doctor patient ratio, further the psychiatrist patient ratio of 0.75 per 100,000 is much below the desirable number of 3 psychiatrist per 100,000. This results in covid duty doctors and health care teams assuming additional responsibility in addressing mental health issues of Covid-19 infected patients while treating their physical ailments. As the entire nation was progressing through the process of gradual "unlocking" during the early part of 2021 there came this devastating second wave in India during April 2021 which changed lives forever. The prevailing restrictions which were easing out were reimposed only with more vigor and intensity. This impacted the socio-economic condition of the country adversely affecting the overall lifestyle of population including working habits, dietary patterns, sleeping schedules, physical and social activities of the people resulting in worsening of both physical and mental health among covid-19 affected cases and the larger population in general. ${ }^{7}$

Mental health well-being is of serious concern among hospital admitted patients of covid-19. Already they are exposed to all the detrimental effects of covid-19 in the society and once they contract the virus they feel helpless. The concept of quarantine and being dragged away and isolated from their near and dear ones at the time of their ill health poses a grave risk to their physical and psychological well-being. They are also isolated from visitors and seeing relatives while battling the illness in the hospital setting. In a country like India connecting each hospitalized covid-19 patient with their relatives through internet during their time of crisis is less likely. This has resulted in an increased feeling of loneliness and being abandoned among the admitted covid-19 positive patients. In a hospital in Wuhan, China, in one of the earliest studies on mental health and covid-19, reported depressive symptoms was found to be in $13.4 \%$ of hospitalized patients with covid- $19 .^{8}$ 
This present study investigates the prevalence of depression, insomnia, and suicidal ideation among the covid-19 affected patients hospitalized, along with a risk factor analysis with respect to their socio-demographic characteristics such as their gender, age, place of residence, economic status of family and presence of preexisting comorbid conditions. The exploratory nature of the study and the fact that no previous study has been effectively conducted during this ongoing second wave of covid-19 in India in this specific cohort, leaves the hypothesis of this study unframed.

The aim of the study is to assess the prevalence of depression, insomnia, and suicidal ideation among covid19 patients admitted in covid wards at Saveetha Medical College and Hospital Chennai during the devastating second wave with mild-to-moderate disease.

To evaluate the socio-demographic risk factors causing increased prevalence of depression, insomnia and suicidal ideation in covid-19 patients admitted in the covid wards.

\section{Materials and Methods Participants and Procedure}

The present cross-sectional study was conducted in 635 Covid-19 infected in-patients with mild-to-moderate disease who were hospitalized during the second wave of Covid-19 in India during the months of April, May, and June 2021 in Saveetha Medical College and Hospital Chennai. It is a single centred observational study in a teaching hospital conducted on covid-19 patients who were having mild-to-moderate covid-19 disease. Covid19 positive patients in high-definition unit and in Intensive Care unit with severe disease were excluded from this study. The inclusion of participants was anonymous and voluntary. Patients with mild symptoms, no oxygen requirement and with a stable oxygen saturation maintaining at $\mathrm{SpO} 295$ and above at room atmosphere were categorised as to be having mild disease. Covid patients with lower respiratory tract involvement maintaining $\mathrm{SpO} 2$ of 95 and above and requiring high flow oxygen administration up to 6 lts/min to maintain SpO2 at 94 and above were categorized to be having moderate disease and were included in the study. The covid-19 positive patients were admitted for 14 days quarantine and recovery. On the 15th day RTPCR covid-19 swab test was repeated to check the covid status of the patient. Patients fulfilling the requirements for home quarantine, ie asymptomatic covid positive cases were not included in the study. As mentioned the covid-19 positive patients in high definition covid units, patients in covid ICU, and patients not consenting to participate were excluded from this study. Patients with pre-existing psychiatric conditions were excluded in the study. ${ }^{33}$

The sample size was calculated based on the admission rate per day of mild and moderate covid cases in the hospital keeping in mind the power of the study $>80 \%$ at the level of significance of $5 \%$. The sample size calculator was used to get an estimate of the sample size in this study. The admission rates, though low in the first half of April 2021, exponentially increased in May 2021 and started reducing in the month of June 2021 following the national lockdown. ${ }^{34}$

To ensure a fair and valid conduct of the study, 10 research assistants who were covid health care staff taking care of covid wards were designated to collect data, motivate patients to complete the questionnaire by providing help with reading out the questions and providing on spot translation to local language. The questionnaire was prevalidated and edited by a previous pilot study conducted on 50 non covid volunteers from the hospital setting. Data from 635 patients were collected and after excluding faulty and incomplete responses 590 were utilized for further analysis. Out of this h $302(51.2 \%)$ were men with the mean age of the participants being $37.8+/-5.6$ years.

\section{Sample Size and Collection}

A total of 635 Covid-19 positive in-patient with mild-tomoderate disease in the age group 20-55 years who were under quarantine in the covid wards were requested to fill the Google questionnaire form along with a separate form for sociodemographic characteristics, comorbidity and habits. The online Google forms were circulated in socialmedia, WhatsApp and Gmail primarily. Patients were asked to fill the Google form using their android phones if they carried one or were asked to fill same through the android tablet available in the covid ward. All participants were clearly explained about nature and purpose of the study and were provided necessary assurances about the confidentiality of the data being collected. Voluntary informed consent was taken from each covid-19 positive patients prior to their participation. Formal ethical approval of the study was obtained from the Institutional research board prior to the commencement of the study.

\section{Socio-Demographic Information}

The Google form A was used to collect socio-demographic information of the patients. The questions asked included 
Age, Gender, Marital status, Having elderly people at home. Any habits of smoking or alcohol or substance abuse, comorbidities eg, asthma, diabetes, hypertension, chronic kidney disease, thyroid disorder, cancers, obesity, chronic heart disease.

\section{Patient Health Care Questionnaire}

Patient health care questionnaire which comprised of 12 questions related to general and psychiatric well being modified from the original version Kroenke, Spitzer and Williams 2001 and Bangla PHQ-9 ${ }^{9,11}$ was validated, prepared and used as an assessment tool. The questions were based on general depression symptoms like feeling sad, difficulty in concentrating, depressed mood, crying spells, loss of appetite, difficulty in carrying out regular activities, hopelessness of the future, feeling of rejection by others, over a period of past 2 weeks or from the time of positive RTPCR covid-19 swab test report. Each question was graded according to 4 item Likert response thus a score of 0 to 48 was assigned depending upon the severity of depression symptoms and duration. $(0=$ not at all, $1=$ few days, $2=$ more than half of the days, $3=$-nearly every day). A score of 20 and above was considered for having depression. Cronbach's alpha was 0.77 for this assessment tool.

\section{COVID Related Insomnia Assessment}

Insomnia was assessed using the modified seven-item Bangla Insomnia Severity Index. ${ }^{10}$ Insomnia related questions included:How satisfied/dissatisfied are you with your current sleep pattern, sleep and wake up patterns, duration of sleep, difficulty in getting sleep and time required to fall asleep, early morning waking up, nightmares and how often, quality of sleep and disturbances, extreme sad feeling after waking up, etc. Each of these items is graded on a four-point Likert scale ( $0=$ very satisfied, $4=$ very dissatisfied) with scores ranging from 0 to 28 . Scores 14 and above indicated presence of insomnia and sleep disturbances. Cronbach's alpha was 0.82 in the present study for insomnia questionnaire.

\section{COVID-19-Related Suicidal Ideation}

Suicidal ideation due to covid-19 infection in patients was assessed with a single direct binary response question. ("Yes"/ "No") and the question was modified based on the previous studies. Suicidal ideation determining scales are complex and requires interlocutor to administer whereas in this study the responses were collected in
Google forms maintaining social distancing no contact technique abiding by the ethical norms approved by the institutional research board. Suicidal ideation is not the primary measurable outcome in this study and it is also a sensitive issue thus it was preferred to use a single response question. ${ }^{12}$

\section{Statistical Analysis}

The data was analysed using Statistical Package for Social Science (SPSS) Version 25.0 for Windows (SPSS Inc., Chicago, IL, USA). Microsoft Excel 2016 was used for early data cleansing and grounding prior to applying SPSS format. The descriptive statistics (ie, means, frequencies, percentages) were used for distribution of the variables in covid-19 patients. Inferential statistics (eg, chi-square tests) were performed to identify significant relationship between outcome variables (depression, insomnia, and suicidal ideation) and the independent variables like the sociodemographic factors and comorbidities. Linear regressions were carried out to identify risk factors for depression and fear of COVID-19. Initially, all the variables were included in the regression model. Then, both forward selection and backward elimination methods were utilized to crosscheck and keep the predictors best fit to the models (eg, gender, marital status, place of residence, educational status, employment status etc). The assumptions (ie, linearity, normality, and homoscedasticity) with the data were checked for both the models before performing the regression analysis. Automated graphs were used to analyse the data.

\section{Results}

Table 1 represents the characteristics of the population and shows the prevalence of depression with respect to the sociodemographic status. Of the total responses analysed $60.1 \%$ were males and $39.9 \%$ were females, $47.4 \%$ of the participants belonged to age group 31 to 50 years, $48.9 \%$ were alcoholic, $20.1 \%$ was diabetic, only $10.1 \%$ of the participants had no comorbidities and $10.6 \%$ of participants were undergoing employment loss. Depressed participants were significantly more likely in females $(x 2=$ 10.362, df $1 \mathrm{p}<0.001)$, unmarried and separated individuals $(\mathrm{x} 2=62.13 d f=2, \mathrm{p}<0.001)$, housewives $(\mathrm{x} 2=$ $28.05, d f=5 . \mathrm{P}<0.001)$, individuals on substance abuse $(\mathrm{x} 2=28.985, d f=3 . \mathrm{P}<0.001)$, with comorbidities $(\mathrm{x} 2=$ 43.41, $d f=7, \mathrm{p}<0.001$ ), and was not significantly associated with having dependent elderly people at home. 
Table I General Characteristics of the Study Sample with $\chi^{2}$ Analysis at Significance Level $=0.05$ (depression)

\begin{tabular}{|c|c|c|c|c|c|c|c|}
\hline \multicolumn{8}{|c|}{ Depression } \\
\hline \multicolumn{8}{|c|}{ Total Score 48} \\
\hline Sociodemographic Factors & Total $n=590$ & $\begin{array}{c}\text { Score }>24 \\
n=237 \\
40.1 \% \\
\text { Yes }\end{array}$ & $\begin{array}{c}\text { Score }<24 \\
n=353 \\
59.9 \% \\
\text { No }\end{array}$ & $\chi^{2}$ value & $d f$ & $\mathrm{p}$ value & Inference \\
\hline \multicolumn{8}{|l|}{ Age Group } \\
\hline $20-30$ & $110(18.6 \%)$ & $42(38.1 \%)$ & $68(61.9 \%)$ & 45.80345 & 2 & $<0.00001$ & The result is significant at $\mathrm{p}<0.05$ \\
\hline $3 \mid-50$ & $280(47.4 \%)$ & 78 (27.8\%) & $202(72.1 \%)$ & & & & \\
\hline $51-60$ & $200(33.8 \%)$ & 117 (58.5\%) & $83(41.5 \%)$ & & & & \\
\hline \multicolumn{8}{|l|}{ Gender } \\
\hline Males & $355(60.1 \%$ & $128(36.1 \%)$ & 237 (63.9\%) & 10.36 & 1 & 0.00129 & The result is significant at $\mathrm{p}<0.05$ \\
\hline Females & 235 (39.9\%) & 109 (46.3\%) & 116 (49.3\%) & & & & \\
\hline \multicolumn{8}{|l|}{ Marital Status } \\
\hline Married & $430(72.8 \%)$ & $|3|(30.4 \%)$ & $299(69.6 \%)$ & 62.13 & 2 & $<0.00001$ & The result is significant at $\mathrm{p}<0.05$. \\
\hline Unmarried/ & $98(16.6 \%)$ & $65(66.3 \%)$ & $33(33.7 \%)$ & & & & \\
\hline Separated & $62(10.5 \%)$ & $4 \mid(66.1 \%)$ & $21(33.9 \%)$ & & & & \\
\hline \multicolumn{8}{|l|}{ Residence } \\
\hline Urban & $228(38.6 \%)$ & $93(40.78 \%)$ & $135(59.2 \%)$ & 33.97 & 2 & $<0.00001$ & The result is significant at $\mathrm{p}<0.05$. \\
\hline Rural & $213(36.1 \%)$ & $58(27.2 \%)$ & 155 (72.7\%) & & & & \\
\hline Suburban & $149(25.2 \%)$ & $86(57.7 \%)$ & $63(42.2 \%)$ & & & & \\
\hline \multicolumn{8}{|l|}{ Occupational Status } \\
\hline Employed & $138(23.3 \%)$ & $49(35.5 \%)$ & $89(64.4 \%)$ & 28.02 & 5 & 0.00004 & The result is significant at $\mathrm{p}<0.05$. \\
\hline Unemployed & $117(19.8 \%)$ & $26(22.2 \%)$ & 91 (77.7\%) & & & & \\
\hline Retired & $64(10.8 \%)$ & $27(42.1 \%)$ & $37(57.8 \%)$ & & & & \\
\hline Housewife & $165(27.9 \%)$ & $84(50.9 \%)$ & $81(49 \%)$ & & & & \\
\hline Student & $43(7.2 \%)$ & $22(48.8 \%)$ & $21(48.8 \%)$ & & & & \\
\hline Job lost & $63(10.6 \%)$ & $29(46 \%)$ & $34(53.9 \%)$ & & & & \\
\hline \multicolumn{8}{|l|}{ Educational Status } \\
\hline No formal education & 94 (15.9\%) & $62(65.9 \%)$ & $32(34 \%)$ & 56.86 & 4 & $<0.00001$ & The result is significant at $\mathrm{p}<0.05$. \\
\hline Primary & $259(43.8 \%)$ & $82(31.6 \%)$ & $177(68.3 \%)$ & & & & \\
\hline Secondary & $112(18.9 \%)$ & $26(23.2 \%)$ & $86(76.7 \%)$ & & & & \\
\hline Graduate & $72(12.2 \%)$ & $40(55.5 \%)$ & $32(44.4 \%)$ & & & & \\
\hline Postgraduate & $53(8.9 \%)$ & $27(50.9 \%)$ & $26(49 \%)$ & & & & \\
\hline \multicolumn{8}{|l|}{ Habits } \\
\hline Smoker & $115(19.4 \%)$ & $56(48.6 \%)$ & $59(51.4 \%)$ & 28.98 & 3 & $<0.00001$ & The result is significant at $\mathrm{p}<0.05$. \\
\hline Alcoholic & $289(48.9 \%)$ & $122(42 \%)$ & $167(58 \%)$ & & & & \\
\hline Substance abuse & $21(3.5 \%)$ & $16(76.1 \%)$ & $5(23.8 \%)$ & & & & \\
\hline Nil & $165(27.9 \%)$ & $43(26 \%)$ & $122(73 \%)$ & & & & \\
\hline \multicolumn{8}{|l|}{ Comorbidities } \\
\hline Diabetic & $119(20.1 \%)$ & $45(37.8 \%)$ & $74(62.1 \%)$ & 43.41 & 7 & $<0.00001$ & The result is significant at $\mathrm{p}<0.05$. \\
\hline Hypertensive & $215(36.4 \%)$ & $62(28.8 \%)$ & $153(71.1 \%)$ & & & & \\
\hline CRF & $21(3.5 \%)$ & $12(57.1 \%)$ & $9(42.8 \%)$ & & & & \\
\hline Cancer & 09 (1.5\%) & $4(44.4 \%)$ & $5(55.5 \%)$ & & & & \\
\hline Obesity & $113(19.1 \%)$ & $43(38 \%)$ & $70(61.9 \%)$ & & & & \\
\hline Chronic heart disease & $23(3.8 \%)$ & $10(43.4 \%)$ & $13(56.5 \%)$ & & & & \\
\hline Thyroid disorder & $28(4.7 \%)$ & $18(64.2 \%)$ & $10(35.7 \%)$ & & & & \\
\hline Nil & $62(10.5 \%)$ & $43(69.3 \%)$ & $19(30.6 \%)$ & & & & \\
\hline \multicolumn{8}{|l|}{ Having Dependent Elderly at Home } \\
\hline Yes & $366(62.03 \%)$ & $142(38.7 \%)$ & $224(61.2 \%)$ & 0.75 & 1 & 0.38 & The result is not significant at $\mathrm{p}<0.05$. \\
\hline No & $224(37.9 \%)$ & $95(42.4 \%)$ & $129(57.5 \%)$ & & & & \\
\hline
\end{tabular}


Insomnia or sleep disturbances was prevalent among $28.8 \%$ of the total study subjects.

Table 2 represents the characteristics of the participant's sociodemographic status in relation with insomnia and risk factors which can lead to insomnia significantly in covid-19 positive patients. Insomniac participants were more likely belonging to 51-60 years of age group ( $\mathrm{x} 2=$ 9.53, $d f=2, \mathrm{p}<0.01)$, female group compared to male $(\mathrm{x} 2=31.63$, df $1, \mathrm{p}<0.001)$, separated or divorced group of participants ( $\mathrm{x} 2=29.276, d f=2, \mathrm{p}<0.001$ ), patients recovering from cancer $(\mathrm{x} 2=19.30, d f=7, \mathrm{p}<0.05)$ and unemployed individuals $(\mathrm{x} 2=25.02, d f=5 \mathrm{p}<0.001)$.

In Table 3 the suicidal ideation was not significantly prevalent in any specific age groups and neither among gender groups. Suicidal ideation was significantly more in the following groups separated or divorced $(\mathrm{x} 2=42.30$, $d f=2, \mathrm{p}<0.001$ ), participants residing in suburban areas $(\mathrm{x} 2=25.28, d f=2, \mathrm{p}<0.001)$, cancer patients $(\mathrm{x} 2=50.01$, $d f=7, \mathrm{p}<0.001)$ and graduates $(\mathrm{x} 2=8.33, d f=4, \mathrm{p}<$ $0.001)$. There was no significant relation of suicidal ideation with substance abuse, smoking, and alcoholism in this study. Though not significant, suicidal ideation was present among students affected with covid 19 (Table 3).

Figure 1 is the graphical representation of the sociodemographic risk factors resulting in depression in covid19 positive hospitalised patients in quarantine.

On regression analysis it was observed that certain characteristics were statistically significant risk factors for depression in quarantined covid-19 hospitalised patients.

These factors include participants of 51-60 years of age, female participants, separated or divorced individuals, participants who underwent job loss, housewives, individuals on substance abuse, patients having thyroid disorders as comorbidity etc.

Having dependent elderly people at home was not a risk factor for depression in this study.

\section{Discussion}

The consequences of covid-19 infection on mental well being is multifactorial in nature. It can be due to the direct detrimental effects of viral infection on the central nervous system as covid-19 infection is a procoagulant state. On the other hand, the severity of hypoxia and its effect on nervous tissue and the exaggerated immunological response with covid-19 infection can have effect on the neurological system in covid-19 patients. Nevertheless, the medical interventions undertaken due to the covid-19 disease progression, social isolation from near and dear ones, and fear of dying due to covid-19 can have an everlasting deep impact on the minds resulting in post covid mental illnesses. The immune response in covid-19 infection is of concern and it is a hyperinflammatory state like that seen in hemophagocytic lymphohistiocytosis. The increased concentrations of serum C-reactive protein, ferritin, and interleukin-6, though short lived can result in changes in mood, sleep disturbances and depression. The link between inflammation and depression is well established in literature and can lead to some of the psychiatric presentations seen among hospitalized covid $=19$ patients. Most patients with severe acute respiratory distress syndrome, as a result of severe COVID-19 illness, showed impairments of memory, attention span, concentration, and mental processing speed even after 1 year of recovery. ${ }^{13}$

There have been suggestions in integrating nonpharmacological measures in improving mental health among covid patients which can effectively treat stress, anxiety, and grief. When therapies directed towards promoting spirituality, physical exercise, behavioural counselling, breathing exercises were included along with regular management of covid-19 there was reduction in feeling of loneliness and enhanced coping and resilience among the covid-19 patients. $^{14}$

The quarantine imposed due to the coronavirus outbreak adversely influenced people's economy because of an increase in the rate of unemployment. This has led to an increased financial crisis among people and decrease in the quality of life. All these factors can put individuals at greater risk for developing adverse psychological symptoms. This present study has been conducted to observe the adverse effects on physical and psychological wellbeing in the covid-19 positive patients who are hospitalized with mild-to-moderate symptoms of covid-19. It is alarming as depression and suicidal ideation has resulted in hospital suicidal deaths in covid-19 patients admitted with mild-to-moderate covid-19 disease in India and other parts of the world. A recent study conducted in Japan has observed the aspect of adverse economic factors responsible for increased fear and insecurity among covid-19 patients, general population, and healthcare workers. ${ }^{15}$ With the recent second wave of covid-19 from April to June 2021 in India the devastation is profound and is going to leave a long-lasting impact on mental wellbeing of the vast population in the country. The state of uncertainty regarding the prognosis and outcome of the covid-19 disease in covid-19 positive hospitalised patients do result in 
Table 2 General Characteristics of the Study Sample with $\chi^{2}$ Analysis at Significance Level $=0.05$ (insomnia)

\begin{tabular}{|c|c|c|c|c|c|c|c|}
\hline \multicolumn{8}{|c|}{ Insomnia } \\
\hline \multicolumn{8}{|c|}{ Total Score 28} \\
\hline Sociodemographic Factors & Total $n=590$ & $\begin{array}{c}S c<14 \\
n=420 \\
(71.1 \%) \\
\text { No }\end{array}$ & $\begin{array}{c}\mathrm{Sc}>14 \\
\mathrm{n}=170 \\
(28.8 \%) \\
\text { Yes }\end{array}$ & $\chi^{2}$ value & $d f$ & p value & Inference \\
\hline \multicolumn{8}{|l|}{ Age Group } \\
\hline $20-30$ & $110(18.6 \%)$ & $79(71.8 \%)$ & 31 (28.9\%) & 9.53 & 2 & 0.0085 & The result is significant at $\mathrm{p}<0.05$ \\
\hline $3 \mid-50$ & $280(47.4 \%)$ & $214(76.4 \%)$ & $66(23.6 \%)$ & & & & \\
\hline $51-60$ & $200(33.8 \%)$ & $127(63.5 \%)$ & $73(36.5 \%)$ & & & & \\
\hline \multicolumn{8}{|l|}{ Gender } \\
\hline Males & $355(60.1 \%)$ & $283(79.7 \%)$ & $72(20.3 \%)$ & 31.63 & I & $<0.00001$ & The result is significant at $\mathrm{p}<0.05$. \\
\hline Females & $235(39.9 \%)$ & 137 (58.2\%) & $98(41.8 \%)$ & & & & \\
\hline \multicolumn{8}{|l|}{ Marital Status } \\
\hline Married & $430(72.8 \%)$ & $332(77.2 \%)$ & $98(22.8 \%)$ & 29.27 & 2 & $<0.00001$ & The result is significant at $\mathrm{p}<0.05$. \\
\hline Unmarried & $98(16.6 \%)$ & $57(58.1 \%)$ & $41(41.9 \%)$ & & & & \\
\hline Separated & $62(10.5 \%)$ & $31(50 \%)$ & $31(50 \%)$ & & & & \\
\hline \multicolumn{8}{|l|}{ Residence } \\
\hline Urban & $228(38.6 \%)$ & $134(58.7 \%)$ & $94(41.3 \%)$ & 30.12 & 2 & $<0.00001$ & The result is significant at $\mathrm{p}<0.05$. \\
\hline Rural & $213(36.1 \%)$ & $162(76 \%)$ & 5 I (24\%) & & & & \\
\hline Suburban & 149 (25.2\%) & $124(83.2 \%)$ & $25(16.8 \%)$ & & & & \\
\hline \multicolumn{8}{|l|}{ Occupational Status } \\
\hline Employed & $138(23.3 \%)$ & $108(78.2 \%)$ & $20(20.8 \%)$ & 25.02 & 5 & $<0.0001$ & The result is significant at $\mathrm{p}<0.05$ \\
\hline Unemployed & $117(19.8 \%)$ & $66(56.4 \%)$ & 51 (43.5\%) & & & & \\
\hline Retired & $64(10.8 \%)$ & $43(67.1 \%)$ & 21 (32.9\%) & & & & \\
\hline Housewife & $165(27.9 \%)$ & 121 (73.3\%) & $44(26.7 \%)$ & & & & \\
\hline Student & $43(7.2 \%)$ & $31(72 \%)$ & $12(27.9 \%)$ & & & & \\
\hline Job lost & $63(10.6 \%)$ & $4 \mathrm{I}(65 \%)$ & $22(35 \%)$ & & & & \\
\hline \multicolumn{8}{|l|}{ Educational Status } \\
\hline No formal education & 94 (15.9\%) & $82(87.2 \%)$ & $12(12.8 \%)$ & 22.0 & 4 & 0.0002 & The result is significant at $\mathrm{p}<0.05$. \\
\hline Primary & $259(43.8 \%)$ & | 85 (7|.4\%) & $74(28.6 \%)$ & & & & \\
\hline Secondary & $112(18.9 \%)$ & $72(64.2 \%)$ & $40(35.8 \%)$ & & & & \\
\hline Graduate & $72(12.2 \%)$ & $4 \mathrm{I}(56.9 \%)$ & $31(43.1 \%)$ & & & & \\
\hline Postgraduate & $53(8.9 \%)$ & $40(75.4 \%)$ & $13(24.6 \%)$ & & & & \\
\hline \multicolumn{8}{|l|}{ Habits } \\
\hline Smoker & $115(19.4 \%)$ & $92(80 \%)$ & $23(20 \%)$ & 9.25 & 3 & 0.02 & The result is significant at $\mathrm{p}<0.05$. \\
\hline Alcoholic & $289(48.9 \%)$ & $193(66.7 \%)$ & $96(33.7 \%)$ & & & & \\
\hline Substance abuse & $21(3.5 \%)$ & $18(85.7 \%)$ & $3(14.3 \%)$ & & & & \\
\hline Nil & 165 (27.9\%) & $117(70.9 \%)$ & $48(29.1 \%)$ & & & & \\
\hline \multicolumn{8}{|l|}{ Comorbidities } \\
\hline Diabetic & $119(20.1 \%)$ & $79(66.3 \%)$ & 40 (33.7\%) & 19.30 & 7 & 0.007 & The result is significant at $\mathrm{p}<0.05$ \\
\hline Hypertensive & $215(36.4 \%)$ & $172(80 \%)$ & $43(20 \%)$ & & & & \\
\hline CRF & $21(3.5 \%)$ & $17(80.9 \%)$ & $4(19.6 \%)$ & & & & \\
\hline Cancer & 09 (1.5\%) & $4(44.4 \%)$ & 5 (55.5\%) & & & & \\
\hline Obesity & $113(19.1 \%)$ & $77(68.1 \%)$ & $36(31.8 \%)$ & & & & \\
\hline Chronic heart disease & $23(3.8 \%)$ & $14(60.8 \%)$ & $9(39.1 \%)$ & & & & \\
\hline Thyroid disorder & $28(4.7 \%)$ & 20 (71.4\%) & $8(28.6 \%)$ & & & & \\
\hline Nil & $62(10.5 \%)$ & $37(59.6 \%)$ & 25 (40.4\%) & & & & \\
\hline \multicolumn{8}{|l|}{ Having Dependent Elderly at Home } \\
\hline Yes & $366(62.03 \%)$ & $268(73.2 \%)$ & $98(26.7 \%)$ & 1.95 & I & 0.16 & The result is not significant at $\mathrm{p}<0.05$. \\
\hline No & $224(37.9 \%)$ & $152(67.8 \%)$ & $72(32.1 \%)$ & & & & \\
\hline
\end{tabular}


Table 3 Shows the Prevalence of Suicidal Ideation as 5\% Among the Study Responses. General Characteristics of the Study Sample with $\chi^{2}$ Analysis at Significance Level $=0.05$

\begin{tabular}{|c|c|c|c|c|c|c|c|}
\hline \multicolumn{8}{|c|}{ Suicidal Ideation } \\
\hline \multicolumn{8}{|c|}{ Total Score 4} \\
\hline Sociodemographic Factors & Total $n=590$ & $\begin{array}{c}\text { sc }<4 \\
560 \\
(94.9 \%) \\
\text { No }\end{array}$ & $\begin{array}{c}s c>4 \\
n=30 \\
(5 \%) \\
\text { Yes }\end{array}$ & $\chi^{2}$ value & $d f$ & p value & Inference \\
\hline \multicolumn{8}{|l|}{ Age Group } \\
\hline $20-30$ & $110(18.6 \%)$ & $106(96.3 \%)$ & $4(3.7 \%)$ & 3.67 & 2 & 0.16 & The result is not significant at $\mathrm{P}<0.05$ \\
\hline $31-50$ & $280(47.4 \%)$ & $269(96 \%)$ & II (4\%) & & & & \\
\hline $51-60$ & $200(33.8 \%)$ & $185(92.5 \%)$ & 15 (7.5\%) & & & & \\
\hline \multicolumn{8}{|l|}{ Gender } \\
\hline Males & $355(60.1 \%)$ & 339 (95.4\%) & $16(4.6 \%)$ & 0.61 & 1 & 0.43 & The result is not significant at $\mathrm{p}<0.05$. \\
\hline Females & 235 (39.9\%) & $221(94 \%)$ & $14(6 \%)$ & & & & \\
\hline \multicolumn{8}{|l|}{ Marital Status } \\
\hline Married & $430(72.8 \%)$ & $42 ।(97.9 \%)$ & $9(2.1 \%)$ & 42.30 & 2 & $<0.00001$ & The result is significant at $\mathrm{p}<0.05$. \\
\hline Unmarried & $98(16.6 \%)$ & $90(91.8 \%)$ & $8(8.2 \%)$ & & & & \\
\hline Separated & $62(10.5 \%)$ & $49(79 \%)$ & $13(21 \%)$ & & & & \\
\hline \multicolumn{8}{|l|}{ Residence } \\
\hline Urban & $228(38.6 \%)$ & $220(96.4 \%)$ & $8(3.6 \%)$ & 25.28 & 2 & $<0.00001$ & The result is significant at $\mathrm{p}<0.05$. \\
\hline Rural & $213(36.1 \%)$ & $210(98.5 \%)$ & $3(1.5 \%)$ & & & & \\
\hline Suburban & $149(25.2 \%)$ & $130(87.2 \%)$ & $19(12.7 \%)$ & & & & \\
\hline \multicolumn{8}{|l|}{ Occupational Status } \\
\hline Employed & $138(23.3 \%)$ & $130(94.2 \%)$ & $8(5.8 \%)$ & 2.09 & 5 & 0.83 & The result is not significant at $\mathrm{p}<0.05$. \\
\hline Unemployed & $117(19.8 \%)$ & 110 (94\%) & $7(6 \%)$ & & & & \\
\hline Retired & $64(10.8 \%)$ & $62(96.8 \%)$ & $2(3.2 \%)$ & & & & \\
\hline Housewife & $165(27.9 \%)$ & $159(96.3 \%)$ & $6(3.7 \%)$ & & & & \\
\hline Student & $43(7.2 \%)$ & $40(93 \%)$ & $3(7 \%)$ & & & & \\
\hline Job lost & $63(10.6 \%)$ & 59 (93.6\%) & $4(6.4 \%)$ & & & & \\
\hline \multicolumn{8}{|l|}{ Educational Status } \\
\hline No formal education & 94 (I5.9\%) & $94(100 \%)$ & 0 & 8.34 & 4 & $<0.0000$ I & The result is significant at $\mathrm{p}<0.05$. \\
\hline Primary & $259(43.8 \%)$ & $248(95.7 \%)$ & II (4.2\%) & & & & \\
\hline Secondary & $112(18.9 \%)$ & $102(91 \%)$ & $10(9 \%)$ & & & & \\
\hline Graduate & $72(12.2 \%)$ & $66(91.6 \%)$ & $6(8.4 \%)$ & & & & \\
\hline Postgraduate & $53(8.9 \%)$ & $50(94.3 \%)$ & $3(5.8 \%)$ & & & & \\
\hline \multicolumn{8}{|l|}{ Habits } \\
\hline Smoker & 115 (19.4\%) & 107 (93\%) & $8(7 \%)$ & 2.23 & 3 & 0.52 & The result is not significant at $\mathrm{p}<0.05$. \\
\hline Alcoholic & $289(48.9 \%)$ & 277 (95.8\%) & $12(4.2 \%)$ & & & & \\
\hline Substance abuse & $21(3.5 \%)$ & $19(90.4 \%)$ & $2(9.6 \%)$ & & & & \\
\hline Nil & $165(27.9 \%)$ & $157(95.1 \%)$ & $8(4.9 \%)$ & & & & \\
\hline \multicolumn{8}{|l|}{ Comorbidities } \\
\hline Diabetic & $119(20.1 \%)$ & $109(91.5 \%)$ & $10(8.5 \%)$ & 50.01 & 7 & $<0.00001$ & The result is significant at $\mathrm{p}<0.05$. \\
\hline Hypertensive & $215(36.4 \%)$ & $213(99 \%)$ & $2(1 \%)$ & & & & \\
\hline CRF & $21(3.5 \%)$ & 20 (95.2\%) & I (4.8\%) & & & & \\
\hline Cancer & $09(1.5 \%)$ & $5(55.5 \%)$ & $4(44.4 \%)$ & & & & \\
\hline Obesity & $113(19.1 \%)$ & $110(97.3 \%)$ & $3(2.7 \%)$ & & & & \\
\hline Chronic heart disease & $23(3.8 \%)$ & $23(100 \%)$ & 0 & & & & \\
\hline Thyroid disorder & $28(4.7 \%)$ & $26(92.8 \%)$ & $2(7.2 \%)$ & & & & \\
\hline Nil & $62(10.5 \%)$ & $54(87 \%)$ & $8(13 \%)$ & & & & \\
\hline \multicolumn{8}{|l|}{ Having Dependent Elderly at Home } \\
\hline Yes & $366(62.03 \%)$ & 345 (94.2\%) & $21(5.7 \%)$ & 0.8516 & 1 & 0.36 & The result is not significant at $\mathrm{p}<0.05$. \\
\hline No & $224(37.9 \%)$ & $215(95.9 \%)$ & $9(4.01 \%)$ & & & & \\
\hline
\end{tabular}




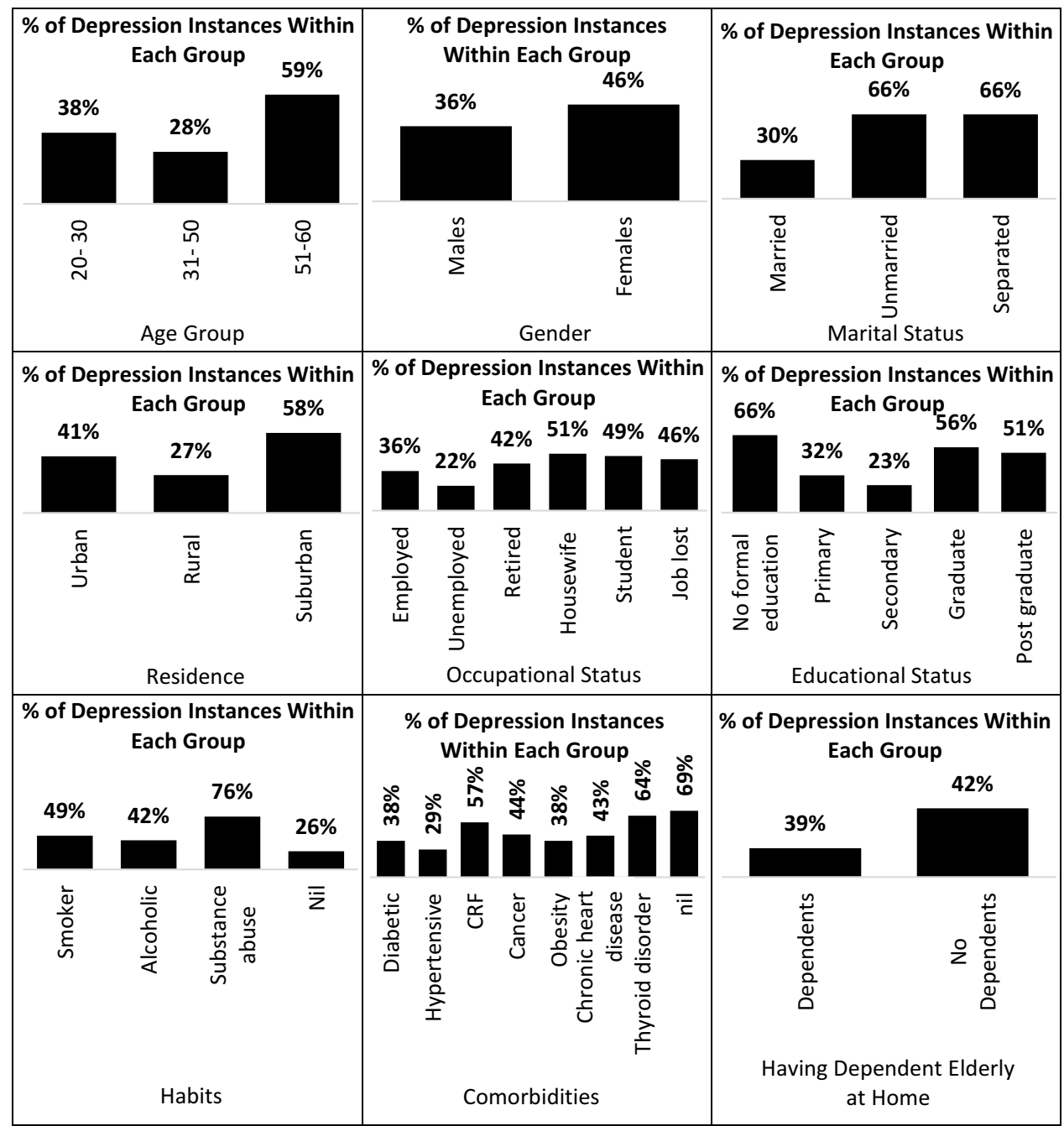

Figure I Column chart representing percentage of depression and sociodemographic risk factors.

increased fear, insecurity, stress, and anxiety. In a systematic review article by Xiong et al 2020 showed the prevalence of anxiety $(6.33 \%$ to $50.9 \%)$, depression $(14.6 \%$ to $48.3 \%)$, posttraumatic stress disorders (7$53.8 \%)$ psychological distress $(34.43 \%$ to $38 \%)$ and stress $(8.1 \%$ to $81.9 \%)$ in the general population during the covid-19 pandemic in China. ${ }^{16}$

Hopelessness, loneliness, crying spells, anger, frustration, and the belief of pandemic which can kill is responsible for increased chances of depression and fear of death due to COVID-19 among the covid-19 patients and general population too. Previous studies have found that fear of death and anxiety states may play a significant role in developing clinical depression in these individuals. ${ }^{17}$ The excessive fear of death due to COVID-19 has contributed to frustration, acute stress, self-harm, and suicidal ideation and even suicides in some covid-19 positive patients. ${ }^{18}$ According to a study conducted by Brooks et al the severity of stress related disturbed mental states are the result of long quarantine periods, the fear of being infected, feeling lonely due to isolation and separation from the members of family. ${ }^{19}$

A recent study from India has discussed the importance of appointing a psychiatrist in the covid wards of medical facilities treating covid-19 patients to include strategies for educating the patients and their attenders about the effects of covid-19 pandemic. The counselling of covid-19 patients, their relatives and even the health care staffs working in covid-19 centres can increase awareness in them about the disease prevention strategies, impart a positive feel on handling this crisis and will target at early detection of depression and suicidal ideation among the vulnerable subjects. ${ }^{20}$

The prevalence of depression of $40.1 \%$ among covid19 patients with mild-to-moderate disease in the present 
study is high and of grave concern. Healthcare providers have to be particularly cautious of the psychological responses of the covid-19 patients while treating physical conditions in covid-19 patients to prevent untoward incidences in the covid wards.

Guo et al highlighted in his observation that covid-19 patients had more risk of developing depression, anxiety disorders and post-traumatic stress syndrome compared to normal controls. Covid-19 positive patients of female gender were comparatively more susceptible to the feeling of helplessness than men and normal covid-19 negative control group. They also established a correlation of depression with serum levels of $\mathrm{C}$ reactive protein thus suggesting an organic cause behind the development of psychological disturbances in covid-19 positive cases. The post covid fatigue, apathy, and depressed mood can thus be linked with the viral infection and increase in inflammatory markers according to the study by Lee and Giuliani et al. ${ }^{21,22}$

In another study by Alkhamees et al from Saudi Arabia conducted on 214 involuntarily quarantined individuals during covid-19 first wave in a facility, it was observed that about one fourth of the study group showed symptoms of stress, anxiety and depression. Thus it was concluded in this study that institutional involuntary mandatory quarantine of individuals had negative psychological consequences especially in vulnerable population. ${ }^{38}$

It has been proved time and again that during crisis times like war, natural disaster, or epidemics like covid-19 there is an increase in domestic violence and women abuse. A study from Hubei province in China, particularly affected by the coronavirus epidemic, showed a threefold increase in rates of domestic family violence during February 2020 confinement period compared with February 2019 non covid-19 times. Though underreported in India, there was an increase in domestic violence during lockdown times in the year $2020 .{ }^{22}$ There are multiple factors like economic loss, loss of near ones, isolation, inability to access medical and social services, inability to access judiciary help, etc. which can lead to increased depression in women compared to men. It has been also observed that being employed and having an understanding partner can to certain extent reduce depression in women. ${ }^{23,24}$ Females generally have a greater risk of developing problems related to mental health issues both during covid-19 times and non-covid times. ${ }^{3,25}$ In the present study too the prevalence of depression among females was $46.3 \%$ compared to $36.05 \%$ in male covid19 patients. This calls for counselling and help being directed towards female covid-19 positive patients so as to improve their mental outlook during quarantine and post recovery.

Suicidal ideation and depression can co-exist especially in confined covid-19 patients thus requiring a regular screening process of mental health for covid-19 positive patients admitted in the wards.

An extensive analytical study conducted by Panigrahi et al in India comprised of 1856 media articles and 4 from scientific articles, 151 covid-19 related suicides were selected for detailed analysis. It was revealed that covid19 related suicide was $80 \%$ in males compared to females though depression was common in women. There was no covid-19 related suicide mentioned in Indian government website. In present study suicidal ideation was pronounced in females about $6 \%$ compared to $4.6 \%$ in males. The factors which led to the suicides in this analysis were mainly due to stigma related to being diagnosed as covid-19 positive and isolation in quarantine after being diagnosed. The study by Panigrahi et al helped to detect risk factors and stressors which can prompt suicide in covid-19 positive patients especially in quarantine. It suggested ways for early detection and prevention strategies by screening covid-19 hospitalised patients with health questionnaire. They also suggested adding a question directly related to suicidal ideation in the standard screening questionnaire by Indian Council of Medical Research which has been done in our present study. ${ }^{26}$

In the present study the suicidal ideation had a prevalence of $5 \%$ which definitely is of concern. The prevalence of suicidal ideation in the present study of $21 \%$ among divorced and separated covid-19 affected individuals is alarming and needs immediate attention in preventing disastrous consequences.

The patients who were smokers, alcoholic or confessed of substance abuse in the present study had a high prevalence of depression $48 \%, 42 \%$ and $76 \%$ respectively. This can be partly attributed to their abstinence and inaccessibility of the above objects during their hospital stay. It has been pointed out in previous studies too that there is increased risk of depression among smokers and alcoholics as such in general population. ${ }^{27}$

Comorbidities worsen the outcome of covid-19, this message has been well communicated in the society during the first wave in India last year and even throughout 2021 so it's possible that individuals with covid-19 and with comorbidities are bound to get worried and show negative 
psychological responses than those with no comorbidities. ${ }^{28}$ In the present study the covid-19 patients with thyroid disorder have $64 \%$ prevalence of depression and prevalence of suicidal ideation is $7.2 \%$ among them.

Suicidal ideation in this study was assessed from the time the individual got covid-19 positive report and admitted in hospital which is relatively a short period and cannot be compared with other studies in other countries where the time frame is not mentioned. ${ }^{28}$ In a crosssectional study by convenience sampling with collection of data by conducting an online survey from 10 western and eastern countries comprising of 25,053 participants (22.7\% males) showed that the UK and Brazil had the lowest odds of suicidal ideation compared to Macau ( $p<$ $0.05)$. It was noted in the above-mentioned study that younger age groups, male participants, married, and differences in health beliefs were risk factors associated with suicidal ideation. ${ }^{29,30}$

Thomas Joiner has put forward certain clear theories (Interpersonal theory of suicide) which can lead to suicidal ideation among individuals for a better understanding of suicidal acts. These include feeling of being an emotional and financial burden on near and dear ones, separation leading to a feeling of desolation, extreme loneliness and attainment of an unique ability to hurt oneself are some of the theories placed forward by him for developing suicidal ideation among individuals. ${ }^{39}$ In this study all of these are applicable for covid-19 patients in isolation with uncertainty of life and economic losses due to covid-19 disease.

Individuals who face a sudden unemployment or job loss are expected to experience acute stress, anxiety, uncertainty, with a feeling of financial constraints especially dependent on other members of the family. In the present study about $10 \%$ of total participants were undergoing job loss, among them $46 \%$ were depressed, $35 \%$ had symptoms suggesting insomnia and $6.4 \%$ had suicidal ideation. In a recent cross-sectional study conducted in India on 100 covid-19 positive inpatients $75 \%$ of covid19 patients had insomnia, 45-50\% had psychic anxiety. Moderate to severe depression was present in $25 \%$ male covid-19 positive patients compared to $16.6 \%$ in female covid-19 positive patients in the above-mentioned study. ${ }^{31}$ In the present study too sleep disturbances are associated with depression and suicidal ideation across all age groups but more so younger people exposed to social media. The covid-19 pandemic, the excessive negative and sad stories in the press due to irresponsible reporting by local media can trigger depression and fear both among general population and covid-19 patients. $^{32}$

Identification of suicidal ideation is often difficult that too when it is concomitant with somatic illness especially with covid-19. As the priority is to get patients cured of the covid-19 symptoms and prevent progression of covid-19 disease, the mental health takes the back seat in a pandemic situation. This is commonly seen among older suicidal adults with somatic illness. Elderly patients seeking help for physical ailments like neurological conditions, pain, oncological issues are vulnerable for suicidal ideation and it is important to address the psychological aspect too and apply appropriate screening. ${ }^{36}$ Patients presenting with covid-19 positive test results and symptoms in the hospital may not show up all the characteristics to make a diagnosis of depression and may have characteristic of demoralisation an emerging psychological construct of increasing interest which has been proposed to be included in the depression assessment scales. This includes the feeling of hopelessness, loneliness, being neglected and in country like India the feel of being a financial and emotional burden to other members of the family. Demoralisation can lead to depressive episodes but it is more sensitive and different from depression. Demoralisation can have an acute onset may be due to sudden ill health, sudden loss and is correlated with suicidal ideation. $^{35,37}$

\section{Clinical Implications of the Study}

The prevalence of depression, insomnia or sleep disturbances, suicidal ideation in present study suggest that attention is needed from health care professionals for regular counselling covid-19 patients admitted in the wards. Mental health support groups visiting covid wards along with efficient online counselling systems should be available to each covid-19 patient admitted in the hospital. The findings need to be further explored to help facilitate the development of better intervention programs and appropriate support services for this vulnerable covid-19 positive hospitalised group.

\section{Limitations}

This study is not without limitations. Firstly, the present study is cross sectional in nature thus the causal relationship between depression, insomnia and suicidal ideation and socioeconomic and demographic characteristics cannot be delineated based on this data alone. The study is limited to relatively small sample size and single centered one. The findings analysed are based on self-reporting of data which too can be biased at different aspects like recall bias, or 
social desirability bias. The present research can be replicated with a bigger and more representative multicenter samples in and outside India.

\section{Conclusion}

The present single centric observation study provides some valuable data on the prevalence of depression, insomnia, and suicidal ideation among covid-19 positive patients and its relationship with sociodemographic characteristics. There was significantly increased prevalence of depression in covid-19 positive patients if the participants were from older age groups, female gender, separated or divorced, having comorbid conditions especially thyroid disorder, with no formal education and recent job loss. About one third of study subjects were having sleep disturbances and insomnia and the risk factors for insomnia was older age group (51-60 years), female gender, separated or divorced participants, cancer patients and unemployed individuals. Suicidal ideation was too significant among separated or divorced group of participants and patients recovering from cancer but no significant relation of suicidal ideation among age groups or gender was observed. These risk factors can assist in screening and identification of vulnerable covid-19 patients admitted in hospital wards thus prompting preventive measures. There is overwhelming need for further studies to assess the mental wellbeing of covid 19 infected patients during and post quarantine thus to direct preventive measures adequately.

\section{Ethical Approval}

All procedures performed in this study involving human participants were in accordance with ethical standards of Saveetha University Institutional Ethics Board Chennai and with the 1975 Helsinki Declaration. The ethical clearance was obtained from Saveetha Medical Institute Ethics Board on 03.03:2021 much prior to commencement of the study and clearance for conducting the study with utmost covid precautions was given by the institution's Ethics Board members.

Informed voluntary consent was obtained from all participants after providing them with information on the study. The information obtained from participants were kept confidential. No names or personal identifiable records or data was used in the study.

\section{Acknowledgment}

The present affiliation of the author is Chettinad Hospital and Research Institute, Chettinad Academy of Research and Education, Kelambakkam, Chennai, India.

\section{Funding}

Self funded.

\section{Disclosure}

The author reports no conflicts of interest for this work.

\section{References}

1. Anand KB, Karade S, Sen S, Gupta RM. SARS-CoV-2: Camazotz's curse. Med J Armed Forces India. 2020;76(2):136-141. doi:10.1016/ j.mjafi.2020.04.008

2. Sijia L, Wang Y, Xue J, Zhao N, Zhu T. The impact of covid 19 epidemic declaration on psychological consequences: a study on active Weibo users. Int $J$ Environ Res Public Health. 2020;17 (6):2032. doi:10.3390/ijerph17062032

3. Wang C, Pan R, Wan X, et al. Immediate psychological responses and associated factors during the initial stage of the 2019 coronavirus disease (COVID-19) epidemic among the general population in China. Int $J$ Environ Res Public Health. 2020;17(5):1729. doi:10.3390/ijerph17051729

4. Xiang Y-T, Yang Y, Li W, et al. Timely mental health care for the 2019 novel coronavirus outbreak is urgently needed. Lancet Psychiatry. 2020;7(3):228-229. doi:10.1016/S2215-0366(20)30046-8

5. Vindegaard N, Benros ME. COVID-19 pandemic and mental health consequences: systematic review of the current evidence. Brain Behav Immun. 2020;89:531-542. doi:10.1016/j.bbi.2020.05.048

6. Pappa S, Ntella V, Giannakas T, Giannakoulis VG, Papoutsi E, Katsaounou P. Prevalence of depression, anxiety, and insomnia among healthcare workers during the COVID-19 pandemic: a systematic review and meta-analysis. Brain Behav Immun. 2020;88:901-907. doi:10.1016/j.bbi.2020.05.026

7. Rawat D, Dixit V, Gulati S, Gulati S, Gulati A. Impact of COVID-19 outbreak on lifestyle behaviour: a review of studies published in India. Diabetes Metab Syndr. 2021;15(1):331-336. doi:10.1016/j. dsx.2020.12.038

8. Dai LL, Wang X, Jiang TC, et al. Anxiety and depressive symptoms among COVID-19 patients in Jianghan Fangcang Shelter Hospital in Wuhan, China. PLoS One. 2020;15(8):e0238416. doi:10.1371/journal.pone. 0238416

9. Chowdhury AN, Ghosh S, Sanyal D. Bengali adaptation of brief patient health questionnaire for screening depression at primary care. J Indian Med Assoc. 2004;102(10):544-547.

10. Mamun MA, Pakpour AH. Psychometric validation of Bangla insomnia severity index: confirmatory factor analysis and rasch analysis. Under-Review. 2020. doi:10.1016/j.dib.2020.106621

11. Kroenke K, Spitzer RL, Williams JB. The PHQ-9: validity of a brief depression severity measure. J Gen Intern Med. 2021;16(9):606-613. doi:10.1046/j.1525-1497.2001.016009606.x

12. Jahan S, Araf K, Gozal D, Griffiths MD, Mamun MA. Depression and suicidal behaviors among Bangladeshi mothers of children with autistic spectrum disorder: a Comparative Study. Asian J Psychiatr. 2020;51:101994. doi:10.1016/j.ajp.2020.101994

13. Rogers JP, Chesney E, Oliver D, et al. Psychiatric and neuropsychiatric presentations associated with severe coronavirus infections: a systematic review and meta-analysis with comparison to the COVID-19 pandemic. Lancet Psychiatry. 2020;7:7.

14. Vahia IV, Jeste DV, Reynolds CF 3rd. Older adults and the mental health effects of COVID-19. JAMA. 2020;324(22):2253-2254. doi:10.1001/jama.2020.21753

15. Shigemura J, Ursano RJ, Morganstein JC, Kurosawa M, Benedek DM. Public responses to the novel 2019 coronavirus (2019-nCoV) in Japan: mental health consequences and target populations. Psychiatry Clin Neurosci. 2020;74(4):281-282. doi:10.1111/pcn. 12988 
16. Xiong J, Lipsitz O, Nasri F, et al. Impact of COVID-19 pandemic on mental health in the general population: a systematic review. J Affect Disord. 2020;277:55-64. doi:10.1016/j.jad.2020.08.001

17. Menzies RE, Sharpe L, Dar-Nimrod I. The relationship between death anxiety and severity of mental illnesses. Br J Clin Psychol. 2019;58(4):452-467. doi:10.1111/bjc.12229

18. Sahoo S, Rani S, Parveen S, et al. COVID-19 pandemic: an emerging concern - a report of 2 cases from India. Asian J Psychiatr. 2020;51: e102104. doi:10.1016/j.ajp.2020.102104

19. Brooks SK, Webster RK, Smith LE, et al. The psychological impact of quarantine and how to reduce it: rapid review of the evidence. Lancet. 2020;395(10227):912-920. doi:10.1016/S0140-6736(20)30460-8

20. Banerjee D. The COVID-19 outbreak: crucial role the psychiatrists can play. Asian J Psychiatr. 2020;50:02014. doi:10.1016/j.ajp.2020.102014

21. Guo Q, Zheng Y, Shi J, et al. Immediate psychological distress in quarantined patients with COVID-19 and its association with peripheral inflammation: a mixed-method study. Brain Behav Immun. 2020;88:17-27. doi:10.1016/j.bbi.2020.05.038

22. Lee $\mathrm{CH}$, Giuliani F. The role of inflammation in depression and fatigue. Front Immunol. 2019;10:1696. doi:10.3389/ fimmu.2019.01696

23. Wanqing Z. Domestic violence cases surge during COVID-19 epidemic. Psychiatry Res. 2020;291:113267.

24. Florence T, van Wijngaarden-cremers Patricia JM. Women's mental health in the time of Covid-19 pandemic. Front Glob Womens Health. 2020;1:17.

25. Tolin DF, Foa EB. Sex differences in trauma and posttraumatic stress disorder: a quantitative review of 25 years of research. Psychol Bull. 2006;132(6):959-992. doi:10.1037/0033-2909.132.6.959

26. Panigrahi M, Pattnaik JI, Padhy SK. COVID-19 and suicides in India: a Pilot Study of reports in the media and scientific literature. Asian J Psychiatr. 2021;57:102560. doi:10.1016/j.ajp.2021.102560

27. Balogun O, Koyanagi A, Stickley A, Gilmour S, Shibuya K. Alcohol consumption and psychological distress in adolescents: a Multi-Country Study. J Adolesc Health. 2014;54(2):228-234. doi:10.1016/j.jadohealth.2013.07.034

28. Chen N, Zhou M, Dong X, et al. Epidemiological and clinical characteristics of 99 cases of 2019 novel coronavirus pneumonia in Wuhan, China: a Descriptive Study. Lancet. 2020;395 (10223):507-513. doi:10.1016/S0140-6736(20)30211-7
29. Newman MS. Review of studies of mental health in Bangladesh with a focus on depression. Int $J$ Ment Health. 2013;42(4):48-77. doi:10.2753/IMH0020-7411420403

30. Teris C, Ching LS, Hong LP, Tao XY. The international research collaboration on COVID-19. global imperative of suicidal ideation in 10 countries amid the COVID- 19 pandemic. Front Psychiatry. 2021;11:1558.

31. Kumar P, Chaudhary R, Chabra S. Prevalence of anxiety and depression among Covid -19 patients admitted to tertiary care hospital. Indian J Soc Psychiatry. 2021;37(1):88-92.

32. Glozier N, Martiniuk A, Patton G. Short sleep duration in prevalent and persistent psychological distress in young adults. The Drive study. Sleep. 2010;33(9):1139-1145. doi:10.1093/sleep/33.9.1139

33. Zhang J, Wang M, Zhao M. The Clinical characteristics and prognostic factors of mild - moderate patients with COVID -19 in a mobile cabin hospital: a retrospective Single- Center Study. Front Public Health. 2020;8:264. doi:10.3389/fpubh.2020.00264

34. Kadam P, Bhalerao S. Sample size calculation. Int J Ayurveda Res. 2010;1(1):55-57. doi:10.4103/0974-7788.59946

35. Costanza A, Di Marco S, Burroni M, et al. Meaning in life and demoralization: a mental-health reading perspective of suicidality in the time of COVID-19. Acta Biomed. 2020;91(4):e2020163.

36. Alessandra C, Andrea A, Michalina R, et al. Suicidality assessment of the elderly with physical illness in the emergency department. Front Psychiatry. 2020;11:940.

37. Costanza A, Baertschi M, Richard-Lepouriel H, Weber K, Berardelli I, Pompili M. Demoralization and Its relationship with depression and hopelessness in suicidal patients attending an emergency department. Int J Environ Res Public Health. 2020;17(7):2232. doi:10.3390/ijerph17072232

38. Alkhamees AA, Aljohani MS, Alghesen MA, Alhabib AT. Psychological distress in quarantine designated facility during COVID-19 pandemic in Saudi Arabia. Risk Manag Healthc Policy. 2020;13:3103-3120. doi:10.2147/RMHP.S284102

39. Joiner T. Why People Die by Suicide. Harvard University Press; 2007.
Journal of Multidisciplinary Healthcare

\section{Publish your work in this journal}

The Journal of Multidisciplinary Healthcare is an international, peerreviewed open-access journal that aims to represent and publish research in healthcare areas delivered by practitioners of different disciplines. This includes studies and reviews conducted by multidisciplinary teams as well as research which evaluates the results or conduct of such teams or healthcare processes in general. The journal covers a very wide range of areas and welcomes submissions from practitioners at all levels, from all over the world. The manuscript management system is completely online and includes a very quick and fair peer-review system. Visit http://www.dovepress.com/testimonials. php to read real quotes from published authors. 